\title{
A psychiatric liaison service for a social services office
}

\author{
An unmet need, a useful innovation or an unnecessary inconvenience?
}

\author{
William Grant, Senior Registrar in Psychiatry, Newcastle General Hospital; and ANNE \\ Richardson, Social Worker, Clifton Mount Sub-office, Grainger Park Road, \\ Newcastle upon Tyne
}

\begin{abstract}
Although there has been considerable interest into the amount of liaison work that general psychiatrists do with general practitioners in primary health care settings, ${ }^{1,2}$ and into the role that social workers can play in liaising with the primary health care team, ${ }^{3}$ less is known about the extent to which general psychiatrists have established liaison links with particular social services offices, what form the liaison takes and whether the liaison has worked satisfactorily.
\end{abstract}

Traditionally, the health and social services have been separate but, encouraged by local enthusiasm and in keeping with government policy as stated in the Royal Commission on the NHS, ${ }^{4}$ in Newcastle at least, a regular liaison service was established between the psychiatric services based at Newcastle General Hospital and four local social services offices.

This article describes the conclusions that we have drawn when the liaison service at one office was reviewed. This was done by asking the social workers involved about the liaison service, getting them to fill in a questionnaire and monitoring the extent to which the liaison service was used for a 10-month period (April 1987-February 1988). This review was performed partly as this liaison service was now in its fifth year of operation and partly as we were aware that other professional groups were beginning to question the value of certain types of liaison work. ${ }^{5}$ Reviewing the literature, we were unable to find much discussion on the role of liaison work between general psychiatrists and local social services office, or on the extent to which such work takes place. We hope that this article will stimulate further discussion.

\section{The present liaison service}

The background to this service and the initial work at one office (Clifton Mount) has already been reported. $^{6}$ The present arrangement at Clifton Mount is that a senior registrar in psychiatry visits the social work office twice per month and is available via the telephone outside these times. One of the social workers (AR) acts as a co-ordinator, ensuring that the other social workers are aware of the psychiatrist's visits. The social workers are encouraged to discuss clients informally with the authors who may give advice, suggest further areas that the social worker could explore or, if indicated, the psychiatrist may see the client with the social worker.

\section{Results of the review}

Is there a perceived need for a liaison service?

There was an overwhelming feeling from the social workers that the liaison service that was being provided was useful and should be kept going, although perhaps in a slightly changed format. Many of the social workers felt that they lacked the knowledge and skills to work effectively with clients with mental health problems and wanted more information both on local mental health services and about specific conditions, especially schizophrenia, eating disorders and drug withdrawal. Thus, while supervision from seniors and advice from colleagues was readily available, it still appeared that a liaison service with the psychiatric service was seen as being useful and important.

\section{If a liaison service is provided, is it used?}

The results of the review showed that over the last ten months 18 regular visits by the psychiatrist had taken place. Thirty-five different people were discussed on 71 occasions. The majority $(85 \%)$ of these people were not under the care of a psychiatrist at the time they were initially discussed and hence without this liaison service there would be nobody that the social worker could turn to for specialised advice.

\section{Do the social workers bring suitable cases to be discussed?}

The cases discussed were, with a few exceptions, very appropriate and were ones on which a psychiatric opinion was often helpful in clarifying the nature of the problem and the action that needed to be taken. It 
had been the intention when the liaison service was established to try to encourage joint visits by the psychiatrist and social worker when this appeared necessary, and 13 clients were seen. The diagnoses made on these 13 people are listed in Table I. Not only were several cases of major psychiatric illness identified, but it was also possible in some cases to clarify that the behaviour exhibited was not part of a psychiatric illness, which allowed appropriate management to proceed.

It was our conclusion that the social workers did bring along suitable cases for discussion; in many cases there was a considerable degree of psychiatric morbidity and these cases would have been more difficult to manage without the ready access to psychiatric advice.

TABle I

Principal diagnosis made on clients the psychiatrist interviewed

\begin{tabular}{lc}
\hline Diagnosis & $\begin{array}{c}\text { Number of } \\
\text { cases }\end{array}$ \\
\hline Schizophrenia & 3 \\
Paranoid psychosis & 3 \\
Depressive illness & 1 \\
Alcohol dependence & 1 \\
Alcoholic brain disease & 1 \\
Personality disorder & 2 \\
No psychiatric diagnosis & 2 \\
\hline
\end{tabular}

Does the liaison service have advantages over the service provided by general practitioners?

While this liaison service did not attempt to take over from general practitioners in the medical management of clients seen by the social workers the liaison did prove valuable in helping in three main areas:

(a) where the client with possible mental health problems did not have a GP

(b) where the GP did not respond to a request to review the patient

(c) where there was a need for an urgent psychiatric assessment.

The liaison service did allow a faster assessment and commencement of psychiatric treatment, or avoidance of inappropriate treatment, than if the patient had been first seen and assessed by the GP and then referred on. In addition, the liaison service allowed some teaching of the social workers to occur which increased their knowledge of the psychiatrist's methods.

The liaison service had additional advantages which included the psychiatrist's specialised knowledge of local services; a wider understanding of the psychodynamic issues leading to an understanding of the problems affecting the client and problems in the client/social worker relationship and easier access to other sources of information such as old psychiatric notes.

We feel that the liaison service complemented the service already provided by local GPs and allowed the social workers ease of access to somebody with specialised training in the field of mental health.

\section{Advantages for the psychiatrist?}

The liaison service did allow cases presently being seen by the psychiatrist to be discussed informally with a social worker, and this resulted in either the cases being passed onto an area team social worker (two cases) or allowed joint management to be undertaken more readily (seven cases). In addition to increasing the psychiatrist's knowledge of the social worker's work, the liaison allowed some patients to be given appropriate help with less time being invested by the psychiatrist.

\section{Are their disadvantages to this type of liaison?}

Although we are enthusiastic about the need to keep the liaison service going, taking into consideration the advantages listed above, there is a need to look to see if the potential disadvantages, especially the time put aside, are justified. The liaison took up one to two hours per fortnight and this meant that we did not feel that other work suffered. The close liaison and the understanding shown about the problems faced by the other disciplines have meant that unrealistic expectations of the social workers or the psychiatrist have been avoided. Our feeling is that much has depended upon a good relationship developing between the social workers and the psychiatrist and commitment and enthusiasm being shown for the liaison on both sides.

\section{Would the same systems work elsewhere?}

We feel that this type of liaison service may not work so well elsewhere. A smaller social service office in a more affluent area may generate fewer referrals and this may affect the enthusiasm on both sides. In addition, where there is going to be a turnover of staff, for example when a senior registrar is involved, a low number of referrals may have a more adverse effect as neither the social workers nor the psychiatrist may have an opportunity to build up the necessary rapport which allows the service to function well.

\section{Future developments}

Although the liaison service will continue, our review suggested that we need to refine our service. The frequency of contact (twice per month) has proven to be correct but the main problems identified were: 
(a) the need to involve student social workers and qualified staff in the discussion of other social workers cases rather than the discussion being between one social worker and the authors

(b) the need for some teaching, perhaps in a seminar form, on psychiatric topics or topics on the interface between psychiatry and social work.

We are planning to feed back to the entire social work team the conclusions of the review and hope that by running a few seminars that we will increase further the social workers' knowledge and make them more aware of mental health problems and of our role in assisting the social workers in dealing with these problems themselves.

\section{Is the liaison service achieving appropriate goals?}

Mitchell ${ }^{1}$ listed six purposes of liaison work. Substituting the word social worker for the word general practitioner gives the following principles:

(a) to help the social worker identify psychiatric morbidity

(b) to assist the social worker to deal directly with as many cases as are within his/her capability.

(c) to help define at what point a referral to specialised psychiatric services is appropriate and to clarify the purposes of the referral

(d) for the psychiatrist to undertake assessment of patients and to initiate joint care

(e) to share the burden of chronically disabled, demanding and dependent patients (f) to explore the limits of the social worker/client and the social worker/psychiatrist relationship in the detection, diagnosis and management of mental health problems.

We feel that our liaison service is fulfilling all these six objectives and we hope that the further modifications to our service will have continued mutual benefits for the psychiatrist, the social workers and above all those with mental health problems.

Our conclusion has been that this liaison service has met a real need, and has proved a useful innovation without adding greatly to our workload.

\section{References}

${ }^{1}$ Mrtchell, A. (1985) Psychiatrists in primary health care settings. British Journal of Psychiatry, 147, 371-379.

${ }^{2}$ Strathdee, G. \& Williams, P. (1986) Mental Illness in Primary Care Settings (eds. Michael Shepherd, Greg Wilkinson \& Paul Williams). London: Tavistock Publications.

${ }^{3}$ CORNEY, R. H. (1988) Social work and primary care - the need for increased collaboration: discussion paper. Journal of the Royal Society of Medicine, 81, 29-30.

${ }^{4}$ DHSS (1979) Royal Commission on the NHS. London: HMSO. Cmnd 7615.

${ }^{5}$ SPECTOR, J. (1984) Clinical psychology and primary care: some dilemmas. Bulletin of the British Psychological Society, 37, 73-76.

${ }^{6}$ LitTle, L. \& O'Grady, J. (1985) Working together. Community Care, No. 547, 22-24.

\section{Community psychiatric nurses in primary care: consumer survey}

\section{Femi Oyebode, Consultant Psychiatrist, (correspondence) Elaine Gadd, Registrar, DAVID BERRY, formerly Senior Registrar, MARY LYNES, Community Psychiatric Nurse, and Patricia LaShley, Community Psychiatric Nurse, John Conolly Hospital, Birmingham B45 9BD}

There has been a dramatic increase in the numbers of community psychiatic nurses (CPNs) in the last decade; in the period 1980-1985 the number grew from 1667 to 2758 , an overall increase of $65 \%$. $^{1}$ Traditionally, CPNs were based within psychiatric institutions. However, in the period 1980-1985 there was growth from $8 \%$ to $16.2 \%$ in the population of CPNs based in health care centres or General Practitioner (GP) surgeries. ${ }^{2}$ Some of the functions of CPNs is also changing, developing away from involvement with chronic psychiatric patients towards patients with minor disorders. CPNs have also argued that work in the community and in GP surgeries is synonymous with primary prevention. ${ }^{3}$

The developments within the CPN service has been accompanied both by an increasing awareness of their professional status and, in some instances, by an increase in identity confusion. Brewer, ${ }^{4}$ for example, argued that there was no function which social workers performed which CPNs could not do as well or better, but others have pointed out the confusion which the blurring of roles can cause. ${ }^{5}$ There have been calls from within CPN ranks for more involvement in the psychotherapies and for 